\title{
Polydopamine-Assisted Rapid One-Step Immobilization of L-Arginine in Capillary as Immobilized Chiral Ligands for Enantioseparation of Dansyl Amino Acids by Chiral Ligand Exchange Capillary Electrochromatography
}

\author{
Yuanqi Gui ${ }^{1,+}$, Baian Ji ${ }^{1,+}$, Gaoyi Yi ${ }^{1}$, Xiuju Li ${ }^{2, *}$, Kailian Zhang ${ }^{1}$ and Qifeng Fu ${ }^{1, *(\mathbb{D}}$ \\ 1 School of Pharmacy, Southwest Medical University, Luzhou 646000, China; \\ 20200599120019@stu.swmu.edu.cn (Y.G.); jibaian1997@163.com (B.J.); \\ yigaoyi169216@163.com (G.Y.); zkl66@swmu.edu.cn (K.Z.) \\ 2 School of Pharmacy, Tongren Polytechnic College, Tongren 554300, China \\ * Correspondence: 1xj_trzy@163.com (X.L.); fuqifeng@swmu.edu.cn (Q.F.); \\ Tel.: +86-856-6909046 (X.L.); +86-830-3161291 (Q.F.) \\ + These authors contributed equally to this work.
}

check for updates

Citation: Gui, Y.; Ji, B.; Yi, G.; Li, X.; Zhang, K.; Fu, Q.

Polydopamine-Assisted Rapid One-Step Immobilization of L-Arginine in Capillary as Immobilized Chiral Ligands for Enantioseparation of Dansyl Amino Acids by Chiral Ligand Exchange Capillary Electrochromatography. Molecules 2021, 26, 1800. https:// doi.org/10.3390/molecules26061800

Academic Editors: Paola Peluso and Victor Mamane

Received: 27 February 2021

Accepted: 21 March 2021

Published: 23 March 2021

Publisher's Note: MDPI stays neutral with regard to jurisdictional claims in published maps and institutional affiliations.

Copyright: (c) 2021 by the authors. Licensee MDPI, Basel, Switzerland. This article is an open access article distributed under the terms and conditions of the Creative Commons Attribution (CC BY) license (https:// creativecommons.org/licenses/by/ $4.0 /)$.

\begin{abstract}
Herein, a novel L-arginine (L-Arg)-modified polydopamine (PDA)-coated capillary (PDA/LArg@capillary) was firstly fabricated via the basic amino-acid-induced PDA co-deposition strategy and employed to constitute a new chiral ligand exchange capillary electrochromatography (CLE-CEC) method for the high-performance enantioseparation of D,L-amino acids (D,L-AAs) with L-Arg as the immobilized chiral ligand coordinating with the central metal ion $\mathrm{Zn}(\mathrm{II})$ as running buffer. Assisted by hydrothermal treatment, the robust immobilization of L-Arg on the capillary inner wall could be facilely achieved within $1 \mathrm{~h}$, prominently improving the synthesis efficiency and simplifying the preparation procedure. The successful preparation of PDA/L-Arg coatings in the capillary was systematically characterized and confirmed using several methods. In comparison with bare and PDA-functionalized capillaries, the enantioseparation capability of the presented CLE-CEC system was significantly enhanced. Eight D,L-AAs were completely separated and three pairs were partially separated under the optimal conditions. The prepared PDA/L-Arg@capillary showed good repeatability and stability. The potential mechanism of the greatly enhanced enantioseparation performance obtained by PDA/L-Arg@capillary was also explored. Moreover, the proposed method was further utilized for studying the enzyme kinetics of L-glutamic dehydrogenase, exhibiting its promising prospects in enzyme assays and other related applications.
\end{abstract}

Keywords: chiral ligand exchange capillary electrochromatography; enantioseparation; L-arginine; polydopamine; enzyme kinetics study

\section{Introduction}

Chirality is one of the crucially fundamental characteristics of nature [1]. A number of compounds which compose the building blocks of life are enantiotropic chemicals, and the different stereostructures and optical rotation performance between the enantiomers have major effects on the metabolism and normal physiological activities of the life systems [2,3]. Amino acids (AAs) are ubiquitous in all forms of life, and they are basic components of proteins and act as signal transmitters [4,5]. Moreover, free AAs also play a crucial part in numerous life activities [6,7]. However, there are striking differences in vital movement between D-AAs and L-AAs. L-AAs have been considered essential in humans, whereas D-AAs are closely correlated with the nervous and endocrine systems [8-10]. Therefore, the question of how to obtain highly optically pure amino acid enantiomers has long been of great significance, especially for the food and pharmaceutical industries. 
Among all the methods for chiral analysis of AAs, chiral ligand exchange capillary electrophoresis (CLE-CE) has recently received tremendous attention in chiral separation of AAs owing to its benefits of short analysis time, high convenience, and controllable enantiomer migration order [11-14]. The chiral recognition mechanism of CLE-CE is based on the formation of diastereomeric ternary metal complexes between the chiral ligands and the analytes [15]. More specifically, chiral separation can be realized owing to the different stability constants of the metal complexes, as shown in the following equations:

$$
\begin{aligned}
& M(L-S e l)_{n}+L-A M(L-S e l)_{n-1}(L-A)+L-S e l \\
& M(L-S e l)_{n}+D-A M(L-S e l)_{n-1}(D-A)+L-S e l
\end{aligned}
$$

where $M$ is the central metal ion; $S e l$ is the chiral selector; $A$ is the analyte. Although CLE-CE has been reported by many academic research studies, it still faces the pressing challenges of limited chiral ligands, unsatisfactory enantioseparation performance, and narrow application range $[16,17]$. In order to address the above issues, two main strategies could be applied. The first is to develop some novel chiral ligands, including AA derivatives, polymer-based chiral ligands, and AA ionic liquids [18-20]. Although good enantioseparation performance of some D,L-AAs can be realized, many of these new ligands are not yet commercially available, and their synthesis processes are also sophisticated and time-consuming. The other alternative is to construct unique CLE capillary electrochromatography (CLE-CEC) systems. The chiral separation mechanism of CLE-CEC is also based on the different stability constants of the ternary metal complexes between the chiral ligands and the analytes. Slightly different from CLE-CE, in CLE-CEC, the chiral ligands can be immobilized on the capillary's inner surface or filled in the column as the free chiral ligand. Whereafter, the D,L-AAs can be separated, benefitting from the strong synergistic effect between the immobilized and free ligands. Therefore, CLE-CEC can effectively combine the great enantioseparation efficiency of CLE-CE and the high recognition of stationary phases, which has aroused much interest [21-26]. For instance, Qi and coworkers synthesized an L-arginine methyl ester-derived block copolymer and applied it as the immobilized ligands coordinated with $\mathrm{Zn}$ (II) and free ligands for enantioseparation of D,L-AAs [9]. Nevertheless, the previously reported CLE-CEC methods encounter certain defects, such as the time-consuming, sophisticated fabrication processes and the overuse of organic solvents in the buffer solution, which has negative effects on biological sample analysis. Therefore, exploiting the facile and rapid strategies to develop an environmentally friendly CLE-CEC system without adding organic solvents for chiral separation is still under urgent demand but challenging.

Mussel-inspired polydopamine (PDA)-derived coatings have attracted great attention in the field of CEC because they could be utilized as the strong linker to immobilize various functional modifiers [27-29]. Owing to this advantage, a few chiral selectors, such as $\beta$-cyclodextrin, protein, and DNA, have been immobilized to the inner surface of the capillary for electrochromatographic enantioseparation through a PDA-assisted modification method [30-32]. However, according to current knowledge, the possible applications of the PDA-assisted modification strategy to immobilize chiral ligands for high-efficiency chiral separation of D,L-AAs with CLE-CEC have not been studied so far.

In previous studies, our group prepared a novel octadecylamine (ODA)-modified PDA-coated capillary through an organic amine-triggered PDA-coating strategy $[33,34]$.

In these cases, ODA was used to induce dopamine polymerization; meanwhile, it was reacted with dopamine and co-deposited into a PDA coating. Inspired by the prior works, we explored the possibility of PDA-assisted immobilization of L-arginine (L-Arg) on the capillary inner wall for establishing an innovative open-tubular CLE-CEC system. Specifically, L-Arg, a basic amino acid with plentiful amino groups, may also be utilized simultaneously as the trigger for the growth of PDA and the chiral ligand modified in the PDA coating via the strong coupling between amine and catechol groups. 
In this work, a novel L-Arg-modified PDA-coated capillary (PDA/L-Arg@capillary) was firstly prepared through the basic amino-acid-induced PDA co-deposition strategy and employed to constitute a new CLE-CEC system for the chiral separation of D,L-AAs with L-Arg as the immobilized ligand coordinating with $\mathrm{Zn}$ (II) in running buffer. Assisted by the hydrothermal treatment, the immobilization efficiency of L-Arg in the PDA coating was drastically increased and the facile and robust co-deposition process could be achieved within $1 \mathrm{~h}$. Figure 1 presents a schematic of the formation of the PDA/L-Arg@capillary. The chemical components and morphologies of the resulting PDA/L-Arg layer were investigated and confirmed with a series of measures. By using this developed PDA/LArg@capillary, high-efficiency enantioseparation of D,L-AAs was easily achieved in the absence of organic solvents in buffer solutions. The excellent repeatability and stability of PDA/L-Arg@capillary were also verified. Moreover, the probable enantioseparation mechanisms of this new CLE-CEC system were investigated. Ultimately, the developed method was further utilized to study the enzyme kinetics of L-glutamic dehydrogenase (LGLDH), exhibiting its promising prospects in enzyme assays and other related applications.<smiles>NCCc1ccc(O)c(O)c1</smiles>

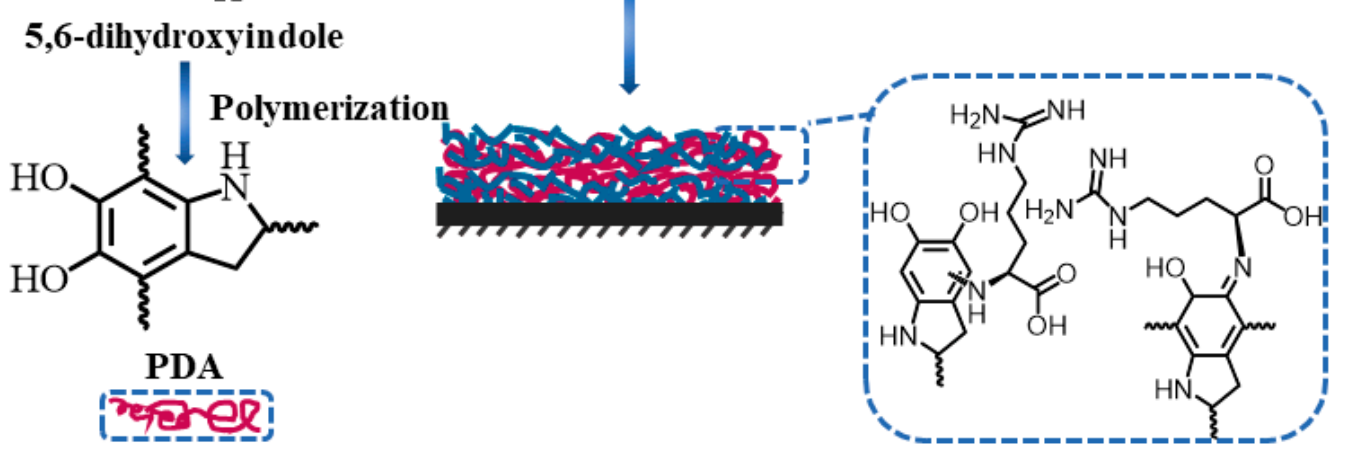

Figure 1. Schematic of the hydrothermal-assisted preparation of PDA/L-Arg@capillary.

\section{Results and Discussion}

\subsection{Characterization of L-Arg/PDA Coating}

\subsubsection{Field Emission Scanning Electron Microscopy (FESEM)}

The inner surface images of the bare capillary and PDA/L-Arg@capillary were characterized by FESEM, respectively. As demonstrated in Figure 2, the inner wall of the bare column is flat and featureless. After hydrothermal treatment with the mixed solution of L-Arg and dopamine, a rough inner surface with some visible small aggregates could be observed, which demonstrated the successful fabrication of an L-Arg modified PDA coating on the capillary inner wall. 


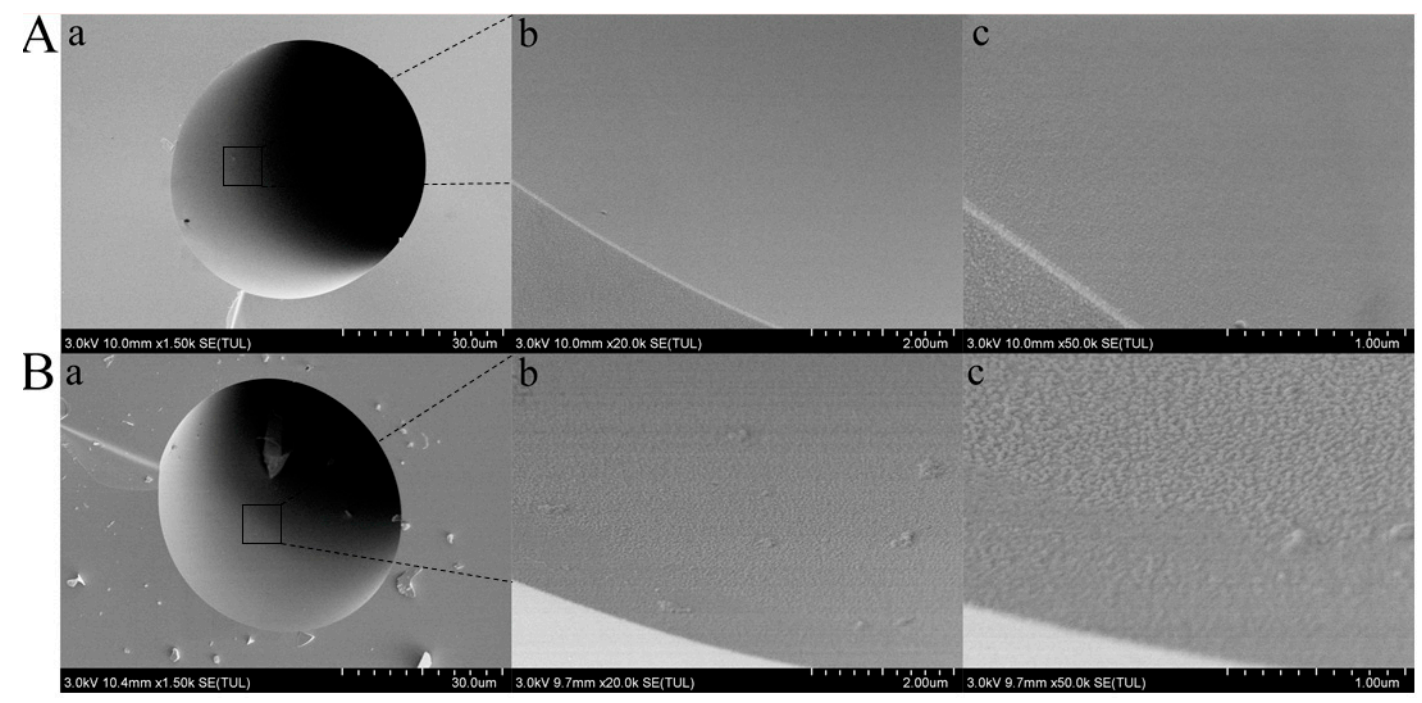

Figure 2. FESEM images of the inner wall of bare capillary (A) and PDA/L-Arg@capillary (B) with different magnification (a. 1.50 k, b. 20.0 k, c. 50.0 k).

2.1.2. Fourier-Transform Infrared Spectroscopy (FTIR) and Attenuated Total Reflectance FTIR (ATR-FTIR)

FTIR and ATR-FTIR measurements were carried out to further confirm the formation of the L-Arg modified PDA coating. Figure 3a shows the FTIR spectra of dopamine, PDA, and PDA/L-Arg composite formed in the solution, which are accompanied by the deposition of PDA and PDA/L-Arg coatings. All three samples exhibited typical absorption of aromatic $\mathrm{C}=\mathrm{C}$ at around $1650,1542 \mathrm{~cm}^{-1}$, catechol $-\mathrm{OH}$ at $3370 \mathrm{~cm}^{-1}$, and amino groups at $3248 \mathrm{~cm}^{-1}$ [35]. On the other hand, the dopamine's characteristic absorption peaks at $1326 \mathrm{~cm}^{-1}$ (C-H bending vibration), $1370 \mathrm{~cm}^{-1}$ (C-O-H deformation vibration), and $1239 \mathrm{~cm}^{-1}$ (C-N stretching vibration) were not discernible in the FTIR spectra of PDA and PDA/L-Arg composite, confirming that the PDA and PDA/L-Arg hybrid samples were free of dopamine and successfully synthesized [36-38]. In addition, the PDA/L-Arg hybrid sample not only retained the characteristic absorption features of PDA but also exhibited a new absorption peak at $1697 \mathrm{~cm}^{-1}$, which could be ascribed to the vibration of $\mathrm{C}=\mathrm{O}$ in L-Arg molecules [39]. In addition, quartz plates whose ingredient was the same as the fused-silica capillary were coated with PDA/L-Arg coatings using the same steps as the PDA/L-Arg@capillary to further validate the co-deposition of PDA/L-Arg. ATR-FTIR measurements were employed to probe the possible PDA/L-Arg coatings on the quartz plates. Figure $3 \mathrm{~b}$ illustrates the ATR-FTIR spectra of the unmodified plate and PDA-functionalized and PDA/L-Arg-functionalized plates. The characteristic absorption of $801 \mathrm{~cm}^{-1}$ (Si-OH) and $982 \mathrm{~cm}^{-1}$ (Si-O-Si) derived from silica were present for all three samples [40]. In comparison with the unmodified plate, PDA- and PDA/L-Arg-coated plates exhibited clear characteristic bands associated with PDA at around $1448 \mathrm{~cm}^{-1}$, $1524 \mathrm{~cm}^{-1}, 1610 \mathrm{~cm}^{-1}, 3211 \mathrm{~cm}^{-1}$, and $3395 \mathrm{~cm}^{-1}$, in accordance with the characterization results of FTIR. Moreover, the PDA/L-Arg-coated plate also exhibited an absorption feature of $\mathrm{C}=\mathrm{O}$ vibration at $1692 \mathrm{~cm}^{-1}$, again confirming the successful modification of L-Arg in the PDA coating.

\subsubsection{Electroosmotic Flow (EOF)}

The EOF mobility of the coated capillary could also be considered as persuasive proof of the functionalization of PDA/L-Arg. As shown in Figure 3c, the EOF mobilities of all capillaries rose gradually with the increasing $\mathrm{pH}$ value from 4.0 to 8.0. The highest EOF values were acquired on the bare capillary owing to the ionization of the surface silanol groups [33]. After the PDA layer was adhered to the capillary inner surface, the EOF values of the PDA-adhered capillary were remarkedly inferior to those of the unmodified capillary 
in the full $\mathrm{pH}$ range due to the presence of groups with positive charges on the PDA layer. As for the PDA/L-Arg@capillary, compared with the PDA-coated column, its EOF value was further reduced due to masking of the silanol groups and the presence of more $\mathrm{N}-\mathrm{H}$ groups on the PDA/L-Arg layer [41].
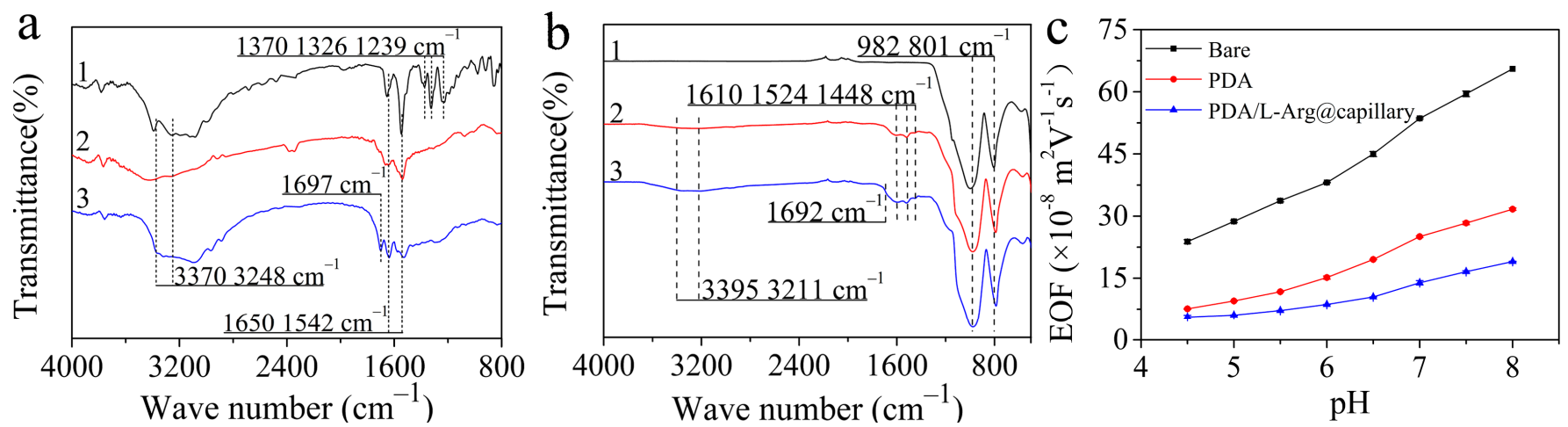

Figure 3. (a) FTIR spectra of dopamine (1), PDA (2), and PDA/L-Arg composite (3). (b) ATR-FTIR spectra of unmodified (1), PDA-coated (2), and PDA/L-Arg-coated quartz sheets (3). (c) The electroosmotic flow mobilities of bare column, PDA-coated column, and PDA/L-Arg@capillary at different buffer pH values ranging from 4.5 to 8.0. EOF marker, DMSO; Buffer, $100.0 \mathrm{mM}$ boric acid, $10.0 \mathrm{mM}$ ammonium acetate, $6.0 \mathrm{mM} \mathrm{ZnSO}_{4}, 6.0 \mathrm{mM}$ L-Arg; Capillary: $50 \mu \mathrm{m}$ i.d. $\times 35 \mathrm{~cm}$ length (26.5 cm effective); sample injection pressure and time at $35 \mathrm{mbar}$ and $5 \mathrm{~s} ; 25^{\circ} \mathrm{C}$; voltage, $-20 \mathrm{kV}$; UV detection at $214 \mathrm{~nm}$.

\subsection{Optimization of PDA/L-Arg@Capillary Preparation}

\subsubsection{Effects of the Molar Ratio of Dopamine and L-Arg on Enantioseparation Capacity}

First, $100 \mathrm{mM}(20 \mathrm{mg} / \mathrm{mL})$ dopamine was chosen as an appropriate concentration for fabricating PDA/L-Arg@capillary because of the optimal enantioseparation effect (Figure S1a). Next, to further ascertain the optimal molar ratio of dopamine to L-Arg in the precursor solution, the effects of different concentrations of L-Arg $(50-350 \mathrm{mM})$ in the presence of $100 \mathrm{mM}$ dopamine on the enantioseparation of the model chiral analyte dansyl D,L-alanine (Dns-D,L-Ala) were intensively investigated. As shown in Figure S1b, with the molar ratio of dopamine to L-Arg increased from 2:1 to 2:5, both the resolutions and migration times of Dns-D,L-Ala gradually increased on the PDA/L-Arg@capillary, which could be attributed to more L-Arg molecules existing in the hybrid coatings and increased interaction strength between PDA/L-Arg coatings and the model analyte. However, the enantioseparation efficiency began to decrease when the molar ratio of dopamine to L-Arg was further increased to $2: 7$, which might be because the excessively high alkalinity of the reaction solution resulted from the excessive L-Arg, which was not conducive to the selfpolymerization of dopamine and the copolymerization between dopamine and L-Arg [42]. Therefore, 2:5 of dopamine to L-Arg was chosen as the optimal molar ratio for fabricating PDA/L-Arg@capillary in the next studies.

\subsubsection{Influences of Hydrothermal Temperature and Time of PDA/L-Arg Layer on} Enantioseparation Capacity

The effect of hydrothermal reaction temperature on enantioseparation performance is illustrated in Figure S2a. As hydrothermal temperature increased $\left(90-120{ }^{\circ} \mathrm{C}\right)$, the migration times and resolution of Dns-D,L-Ala gradually increased, which indicated that the polymerization and deposition rate of PDA greatly increased and more and more L-Arg molecules were immobilized in the hybrid coating via Michael addition and Schiff-base reactions between PDA and L-Arg molecules. When the temperature further increased up to $160^{\circ} \mathrm{C}$, the enantioseparation performance decreased gradually, which might be because the excessive reaction temperature led to the partial carbonization and detachment of the PDA/L-Arg coating (Figure S3). We also investigated the influence of reaction time with the fixed hydrothermal reaction temperature at $120^{\circ} \mathrm{C}$. As revealed by Figure $\mathrm{S} 2 \mathrm{~b}$, the 
maximized resolution and theoretical plate numbers of the model analyte can be observed when the reaction time was up to $1 \mathrm{~h}$. As the reaction time reached $1.5 \mathrm{~h}$, the chiral separation efficiency decreased dramatically. To summarize, the PDA/L-Arg@capillary modified using the hydrothermal method at $120^{\circ} \mathrm{C}$ for $1 \mathrm{~h}$ was selected in the following studies.

\subsection{CLE-CEC Operation Conditions Optimization}

The components and properties of the buffer solution, such as buffer $\mathrm{pH}$, central ion concentration, and the ratio of $\mathrm{Zn}$ (II) to $\mathrm{L}-\mathrm{Arg}$, play key roles in the enantioseparation performance of PDA/L-Arg@capillary. Three pairs of Dns-D,L-AAs, including Dns-D,LAla, Dns-D,L-aspartate (Dns-D,L-Asp), and Dns-D,L-serine (Dns-D,L-Ser), were chosen as the model compounds. The effect of buffer $\mathrm{pH}$ ranging from 7.6 to 8.4 on the separation performance is illustrated in Figure $4 \mathrm{a}$. The recognition of the tested compounds continuously increased as the $\mathrm{pH}$ values increased from 7.6 to 8.0. As the $\mathrm{pH}$ value of the buffer was greater than 8.0 , the resolution of the three analytes began to decrease. On the other hand, the influences of $\mathrm{Zn}$ (II) ion concentrations in the running buffer were also examined in the range of $1.0-8.0 \mathrm{mM}$. As revealed by Figure $4 \mathrm{~b}$, while the concentration ratio of $\mathrm{Zn}$ (II) to L-Arg was fixed at 1:1, the best separation effect was obtained with the usage of $6.0 \mathrm{mM} \mathrm{Zn(II)} \mathrm{in} \mathrm{the} \mathrm{running} \mathrm{buffer.} \mathrm{Furthermore,} \mathrm{Figure} 4 \mathrm{c}$ depicts the results of varying the concentration ratio of $\mathrm{Zn}(\mathrm{II})$ to $\mathrm{L}-\mathrm{Arg}$ from 3:1 to 3:5. The resolution continuously increased with the concentration ratio of $\mathrm{Zn}$ (II)/L-Arg from 3:1 to 1:1. Further increase in the concentration ratio would lead to the deterioration of enantioseparation effects. Furthermore, the influence of the applied voltage on enantioseparation was also studied (Figure S4). Taking account of the shortest retention time and best resolution, the operating voltage was set at $-20 \mathrm{kV}$ for further analysis. Thus, the CLE-CEC enantioseparation experiments were conducted by using an applied voltage of $-20 \mathrm{kV}$ and a buffer solution at pH 8.0 containing $6.0 \mathrm{mM}$ L-Arg and $\mathrm{Zn}(\mathrm{II})$.
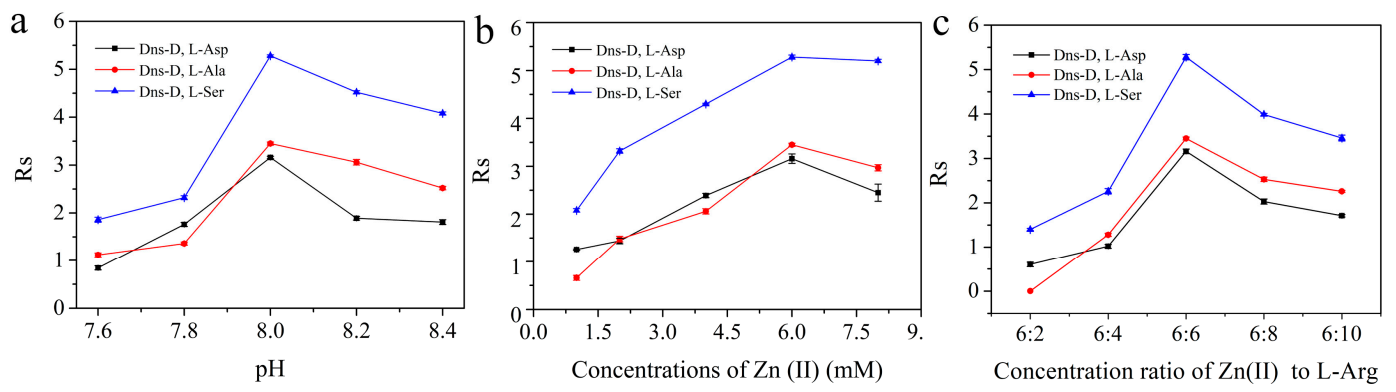

Figure 4. Effects of buffer $\mathrm{pH}$ (a), Zn(II) concentration (b), and the concentration ratio of $\mathrm{Zn}$ (II) to L-Arg (c) on the resolution of Dns-D,L-AAs. Chiral ligand exchange capillary electrochromatography conditions, $100.0 \mathrm{mM}$ boric acid, $10.0 \mathrm{mM}$ ammonium acetate at different $\mathrm{pH}$ and concentrations of $\mathrm{Zn}(\mathrm{II})$ and L-Arg. Other conditions are the same as Figure 3.

\subsection{Enantioseparation Performance of PDA/L-Arg@Capillary}

In order to further demonstrate the excellent enantioseparation performance of the developed CLE-CEC system with immobilized L-Arg chiral ligands, except for the aforementioned three Dns-D,L-AAs, it was further used for the enantioseparation of another eight Dns-D,L-AAs with the optimal conditions. As shown in Table S1, only Dns-D,L-Ser could be completely separated (Rs $>1.50$ ) on the bare column among all eleven Dns-D,LAAs. By contrast, complete separation of eight Dns-D,L-AAs and partial separation of three Dns-D,L-AAs were successfully obtained on the PDA/L-Arg@capillary when using the same electrophoresis conditions, demonstrating the superior enantioseparation ability of the presented CLE-CEC method. In addition, the developed new CLE-CEC method without using organic solvent in the mobile phase possesses a more preferable chiral recognition capability than other previously recorded CLE-CEC methods, further indicating 
the great potential of a PDA-assisted chiral ligand modification strategy for constructing a high-performance CLE-CEC system (Table S2) [8,9,26,43,44].

\subsection{Repeatability and Stability of PDA/L-Arg@Capillary}

Under the optimal CLE-CEC operation conditions, the repeatability and stability of the PDA/L-Arg@capillary was evaluated based on the relative standard deviations (RSDs) of retention time of Dns-D,L-AAs. The RSDs of intra-day, inter-day, and column-to-column were all below 5.8\% (Table S3). Moreover, PDA/L-Arg@capillary could be performed for 80 consecutive injections without significant signs of degradation in the retention time and the enantioseparation performance (Figure S5). These results confirmed that the PDA/LArg@capillary had good repeatability and stability, proving its promising prospects for practical application.

\subsection{Exploration of Enantioseparation Scheme in Presented CLE-CEC}

Chiral separation can be realized because of the varied stability of diastereomeric ternary mixed central metal ion between the chiral ligand and the analytes [15]. As mentioned above, baseline separation of eight Dns-D,L-AAs could be realized on the presented CLE-CEC systems. In contrast, only Dns-D,L-Ser was baseline separated and two Dns-D,L-AAs even had no signs of separation on the bare column. Furthermore, the chiral recognition capability on the PDA-coated capillary was also investigated. As can be seen in Figure 5, the resolutions of the model analyte obtained on the PDA-coated capillary were only slightly higher than that of the bare column, which was much lower than that of the PDA/L-Arg@capillary. Therefore, these results showed that the mobility differences in the ternary complexes on the bare and PDA-coated capillary were so slight that satisfactory enantioseparation effects were quite difficult to achieve. On the other hand, when the PDA/L-Arg@capillary was utilized in the absence of the free L-Arg in the running buffer, its enantioseparation performance was also unsatisfactory. Therefore, as depicted in Figure 6, it can be deduced that the excellent enantioseparation performance of the developed CLE-CEC system benefited from the strong synergistic effect between the immobilized L-Arg in the PDA/L-Arg coating and the free ligands in the buffer solutions.

\subsection{Quantitative Determination of $D, L-G l u$}

Since L-glutamic acid (L-Glu) was adopted as the substrate of L-GLDH, the quantitative determination of Dns-D,L-Glu was conducted using the proposed method. As a result, the detection limits and quantification limits of Dns-D,L-Glu were 15 and $50 \mu \mathrm{g} / \mathrm{mL}$, respectively. The other data, including the good linear relationship and wide linearity ranges of Dns-D, L -Glu, are summarized in Table S4. These results demonstrated that the fabricated PDA/L-Arg@capillary had the potential for the enzyme kinetic study of L-GLDH.
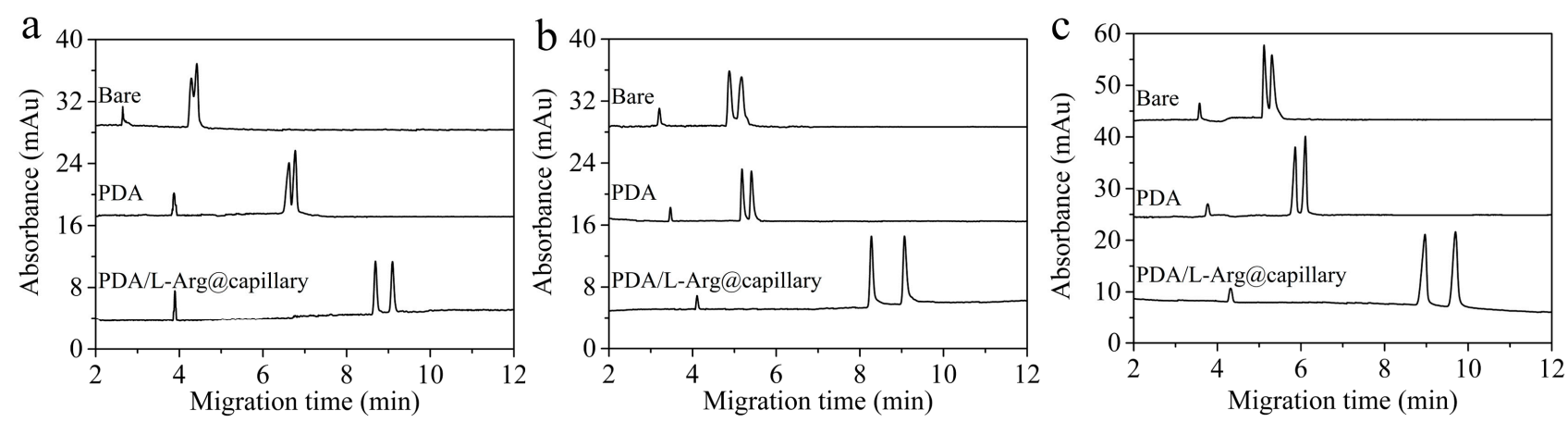

Figure 5. Electropherograms of Dns-D,L-Asp (a), Dns-D,L-Ser (b), and Dns-D,L-Ala (c) on bare, PDA-coated column, and PDA/L-Arg@capillary. Buffer pH at 8. Other CE experimental conditions are the same as Figure 3. 


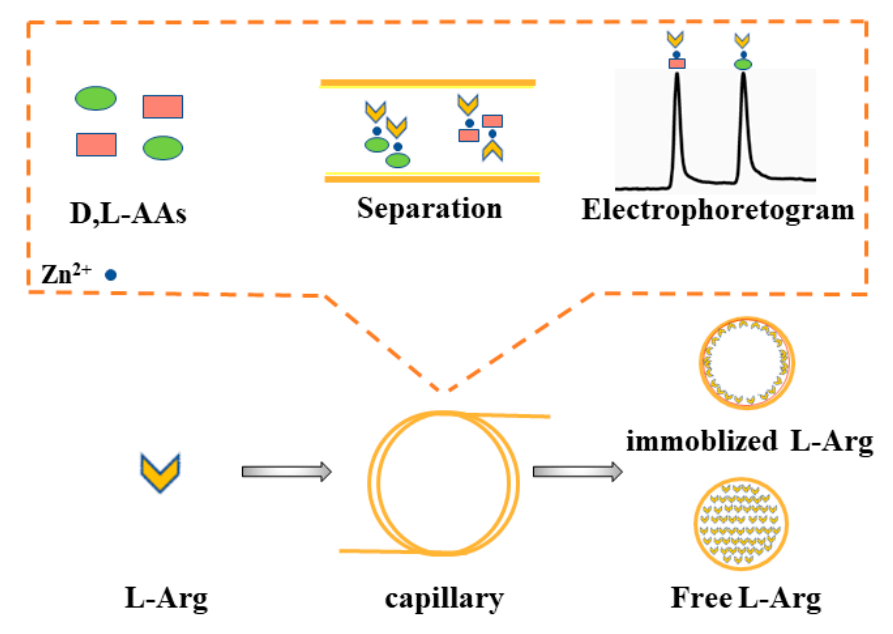

Figure 6. The possible mechanism of the CLE-CEC enantioseparation process.

\subsection{Enzyme Kinetic Study of L-GLDH}

L-GLDH is a key enzyme for amino acid metabolism and urea production. In order to further illustrate the application potential and validate the practicability of the CLE-CEC system, the enzyme kinetic study of L-GLDH was performed by determining the maximum rate $\left(\mathrm{V}_{\max }\right)$ and Michaelis-Menten's constant $\left(\mathrm{K}_{\mathrm{m}}\right)$. Based on the changes in substrate peak area, the values of $\mathrm{V}_{\max }$ and $\mathrm{K}_{\mathrm{m}}$ were calculated to be $414.94 \mathrm{mM} / \mathrm{min}$ and $5.41 \mathrm{mM}$. The data were similar to previously reported values [45], confirming the reliability of the developed CLE-CEC method in enzyme kinetics study.

\section{Materials and Methods}

\subsection{Materials and Chemicals}

D,L-amino acid enantiomers, dansyl chloride (Dns-Cl) and lithium carbonate, were purchased from Macklin Reagent Co., Ltd. (Shanghai, China). Dopamine hydrochloride, L-Arg, and zinc sulfate $\left(\mathrm{ZnSO}_{4}\right)$ were purchased from Adamas Reagent Co., Ltd. (Shanghai, China). L-GLDH was provided by YuanYe Bio-Technology Co., Ltd. (Shanghai, China). Ultra-pure water was purified through an AWL-1002-H water purification system (Aquapro International Company LLC., Chongqing, China).

\subsection{Apparatus}

All the CE separations were conducted on an Agilent 7100 3D CE system (Agilent Technologies, Waldbronn, Germany). The $\mathrm{pH}$ values of the buffer solutions were ad-justed by a FiveEasy PlusTM-FE28 (Mettler Toledo, Shanghai, China). FESEM images were recorded on SU-8020 (Hitachi, Japan). The chemical components on the surface of the quartz plate were detected with ATR-FTIR spectroscopy (Nicolet iS50, Thermo Scientific Inc., Madison, WI, USA).

\subsection{Buffer Solution and Sample Solution Preparation}

The CLE-CEC running buffer ( $\mathrm{pH} 8.0$, adjusted by Tris) was composed of $100 \mathrm{mM}$ boric acid, $10 \mathrm{mM}$ ammonium acetate, $6 \mathrm{mM} \mathrm{L-Arg}$, and $6 \mathrm{mM} \mathrm{ZnSO}_{4}$. Standard sample solutions of $2.0 \mathrm{mg} / \mathrm{mL} \mathrm{D,L-AAs} \mathrm{were} \mathrm{prepared} \mathrm{in} 40 \mathrm{mM}$ lithium carbonate buffer (adjusted to $\mathrm{pH} 9.5$ with $0.1 \mathrm{M} \mathrm{HCl}$ ), then diluted to the desired concentrations with lithium carbonate solution for further analysis. For derivatization, $1.0 \mathrm{~mL}$ Dns-Cl $(1.5 \mathrm{mg} / \mathrm{mL}$, dissolved in acetonitrile) and $1.0 \mathrm{~mL}$ D,L-AAs were dissolved directly in $1.0 \mathrm{~mL}$ lithium carbonate buffer. The mixture was gently shaken for $2 \mathrm{~min}$ and then allowed to react at room temperature for $30 \mathrm{~min}$ away from light. All solutions were filtrated with $0.45-\mu \mathrm{m}$ pore size polyethersulfone membrane and degassed by sonication for $3 \mathrm{~min}$ before use. 


\subsection{CLE-CEC Procedures}

Before being measured, the modified capillaries $(50 \mu \mathrm{m}$ i.d. $\times 35 \mathrm{~cm}$ length; effective length, $26.5 \mathrm{~cm}$ ) were flushed with running buffer for $15 \mathrm{~min}$, and each $3 \mathrm{~min}$ with distilled water and buffer solution between consecutive injections. All samples were introduced hydrodynamically by $35 \mathrm{mbar}$ for $5 \mathrm{~s}$ and separated with an operating voltage of $-20 \mathrm{kV}$. The wavelength for detection was $214 \mathrm{~nm}$, and the temperature of CLE-CEC procedures was maintained at $25^{\circ} \mathrm{C}$.

\subsection{Fabrication of PDA/L-Arg@Capillary}

The PDA/L-Arg@capillaries used in this study were facilely fabricated through filling the bare column with a mixture of dopamine and L-Arg, and then hydrothermal-assisted reacting at high temperature for a period. The preparation process is shown in Figure 1. Briefly, prior to modification, the capillary was accustomed to flushing using methanol (30 $\mathrm{min}), 1 \mathrm{M} \mathrm{NaOH}$ (30 min), ultra-pure water (5 min), $1 \mathrm{M} \mathrm{HCl}(30 \mathrm{~min})$, and ultra-pure water (5 min). Subsequently, the capillary was dried with nitrogen stream. The preconditioned capillary was pumped with a freshly prepared mixture consisting of $250 \mathrm{mM} \mathrm{L-Arg}$ and $20 \mathrm{mg} / \mathrm{mL}$ dopamine for $5 \mathrm{~min}$, then placed into the Teflon-lined bomb. Afterwards, the sealed Teflon-lined bomb was placed in an oven at $120^{\circ} \mathrm{C}$ for $1 \mathrm{~h}$ to in situ grow an L-Arg/PDA layer on the capillary inner wall. Finally, the obtained capillary was washed with water and named the PDA/L-Arg@capillary.

\subsection{Enzyme Kinetics Study of L-GLDH}

The kinetic constants of L-GLDH were calculated by the proposed method. Various concentrations of L-Glu (dissolved in $250 \mathrm{mM}$ phosphate buffer, adjusted to $\mathrm{pH}$ at 8.5) as the substrates were incubated with L-GLDH for $5 \mathrm{~min}$ at $40{ }^{\circ} \mathrm{C}$. Afterwards, the enzymatic reaction was ceased by heating in boiling water for $15 \mathrm{~min}$, and then centrifuged for $15 \mathrm{~min}$ (at 10,000 rpm). Then, the supernatants were extracted and derived using Dns-Cl. For accurate calculation of substrate concentration, different concentrations of Dns-D,L-Glu solutions from 15 to $800 \mu \mathrm{g} / \mathrm{mL}$ were applied to CLE-CEC, and then the calibration curve was constructed.

\section{Conclusions}

In summary, a novel CLE-CEC method was firstly developed with L-Arg as the immobilized chiral ligand for D,L-AAs enantioseparation. The hydrothermal-assisted in-situ PDA-based co-deposition strategy for immobilizing L-Arg chiral ligands could effectively avoid the time-consuming and sophisticated fabrication processes of the previously reported modification method. Benefitting from the strong synergistic effect between the immobilized L-Arg in the PDA/L-Arg coating and the free ligands in the buffer solutions, complete separation of eight Dns-D,L-AAs and partial separation of three Dns-D,L-AAs were successfully achieved on the constructed CLE-CEC system without the use of organic solvent in the running buffer. The fabricated PDA/L-Arg@capillary exhibited satisfactory repeatability and stability. Moreover, the presented method could further be utilized for studying the enzyme kinetics of L-GLDH, exhibiting its promising prospects in enzyme assays and other related applications.

Supplementary Materials: The following are available online: Apparatus, buffer solution and sample solution preparation, Figure S1: Influence of dopamine concentration and the molar ratio of dopamine to L-Arg on the enantioseparation, Figure S2: Effect of reaction temperature, reaction time on the enantioseparation and theoretical plate numbers, Figure S3: Digital photographs of PDA/LArg hybrid-coated quartz plates fabricated under different reaction temperatures or different reaction times, Figure S4: Influence of applied voltages on the enantioseparation, Figure S5: Continuous electrophoresis operation tests, Table S1: Comparison of enantioseparation performance for PDA/LArg-coated and bare capillaries, Table S2: Comparison of enantioseparation performance for different CLE-CEC systems, Table S3: Relative standard deviations of the retention time of Dns-D,L-AAs in 
intra-day and inter-day and column-to-column, Table S4: Quantitative features of the CLE-CEC method for determination of D-Glu and L-Glu.

Author Contributions: Conceptualization, methodology, Q.F.; validation, K.Z.; formal analysis, X.L.; investigation, Y.G. and B.J.; data curation, Y.G. and G.Y.; writing-original draft preparation, Y.G.; writing-review and editing, Q.F.; visualization, X.L.; supervision, Q.F.; project administration, Q.F. and X.L.; funding acquisition, Q.F. All authors have read and agreed to the published version of the manuscript.

Funding: This research was funded by the National Natural Science Foundation of China (Grant No. 21804113 and 22074126), the Sichuan Science and Technology Program (Grant No. 2021JDRC0104), the Science and Technology Transformation Cooperation Project of Luzhou Municipal Government and Southwest Medical University (Grant No. 2019LZXNYDC03) and the Talent Introduction Project of Southwest Medical University (Grant No. 090300040005).

Data Availability Statement: The data presented in this study are available on request from the corresponding author.

Conflicts of Interest: The authors declare no conflict of interest.

\section{References}

1. Chen, J.; Liang, R.P.; Wu, L.L.; Qiu, J.D. One-step preparation and application of mussel-inspired poly(norepinephrine)-coated polydimethylsiloxane microchip for separation of chiral compounds. Electrophoresis 2016, 37, 1676-1684. [CrossRef] [PubMed]

2. Wang, Z.; Yang, C.; Yan, X. Polysiloxane assisted fabrication of chiral crystal sponge coated capillary column for chiral gas chromatographic separation. J. Chromatogr. A 2019, 1608, 460420. [CrossRef] [PubMed]

3. Liu, Y.; Sombra, L.L.; Stege, P.W. Enantiomeric separation of $\beta$-blockers and tryptophan using heparin as stationary and pseudostationary phases in capillary electrophoresis. Chirality 2018, 30, 988-995. [CrossRef]

4. Zhang, J.-H.; Xie, S.-M.; Zi, M.; Yuan, L.-M. Recent advances of application of porous molecular cages for enantioselective recognition and separation. J. Sep. Sci. 2019, 43, 134-149. [CrossRef]

5. $\quad$ Liang, R.-P.; Wang, X.-N.; Liu, C.-M.; Meng, X.-Y.; Qiu, J.-D. Facile preparation of protein stationary phase based on polydopamine/graphene oxide platform for chip-based open tubular capillary electrochromatography enantioseparation. J. Chromatogr. A 2014, 1323, 135-142. [CrossRef]

6. Chen, M.; Rong, L.; Chen, X. A simple and sensitive detection of glutamic-pyruvic transaminase activity based on fluorescence quenching of bovine serum albumin. RSC Adv. 2015, 5, 103557-103562. [CrossRef]

7. Turle-Lorenzo, N.; Maurin, B.; Puma, C.; Chezaubernard, C.; Morain, P.; Baunez, C.; Nieoullon, A.; Amalric, M. The dopamine agonist piribedil with L-DOPA improves attentional dysfunction: Relevance for Parkinson's disease. J. Pharmacol. Exp. Ther. 2006, 319, 914-923. [CrossRef]

8. Feng, W.; Qiao, J.; Li, D.; Qi, L. Chiral ligand exchange capillary electrochromatography with dual ligands for enantioseparation of D,L-amino acids. Talanta 2019, 194, 430-436. [CrossRef] [PubMed]

9. Zhao, L.; Qiao, J.; Zhang, K.; Li, D.; Zhang, H.; Qi, L. Construction of chiral ligand exchange capillary electrochromatography for $\mathrm{d}, \mathrm{l}$-amino acids enantioseparation and its application in glutaminase kinetics study. J. Chromatogr. A 2018, 1548, 104-110. [CrossRef] [PubMed]

10. Kiriyama, Y.; Nochi, H. D-Amino Acids in the Nervous and Endocrine Systems. Scientifica (Cairo) 2016, 2016, 6494621. [CrossRef] [PubMed]

11. Greno, M.; Marina, M.L.; Castro-Puyana, M. Enantioseparation by Capillary Electrophoresis Using Ionic Liquids as Chiral Selectors. Crit. Rev. Anal. Chem. 2018, 48, 429-446. [CrossRef]

12. Mu, X.; Qi, L.; Shen, Y.; Zhang, H.; Qiao, J.; Ma, H. A novel chiral ligand exchange capillary electrophoresis system with amino acid ionic liquid as ligand and its application in screening D-amino-acid oxidase inhibitors. Analyst 2012, 137, 4235-4240. [CrossRef] [PubMed]

13. Schmid, M.G.; Grobuschek, N.; Lecnik, O.; Gübitz, G. Chiral ligand-exchange capillary electrophoresis. J. Biochem. Biophys. Methods 2001, 48, 143-154. [CrossRef]

14. Aizawa, S.; Kodama, S. Mechanism of change in enantiomer migration order of enantioseparation of tartaric acid by ligand exchange capillary electrophoresis with $\mathrm{Cu}(\mathrm{II})$ and $\mathrm{Ni}(\mathrm{II})$-D-quinic acid systems. Electrophoresis 2012, 33, 523-527. [CrossRef] [PubMed]

15. Schmid, M.G.; Gubitz, G. Enantioseparation by chromatographic and electromigration techniques using ligand-exchange as chiral separation principle. Anal. Bioanal. Chem. 2011, 400, 2305-2316. [CrossRef]

16. Liu, L.; Bao, P.; Qiao, J.; Zhang, H.; Qi, L. Chiral ligand exchange capillary electrophoresis with L-dipeptides as chiral ligands for separation of Dns-D,L-amino acids. Talanta 2020, 217, 121069. [CrossRef]

17. Maccarrone, G.; Contino, A.; Cucinotta, V. The study of solution equilibria in chiral capillary electrophoresis by the ligandexchange mechanism. TrAC Trends Anal. Chem. 2012, 32, 133-153. [CrossRef] 
18. Xue, S.; Ren, S.; Wang, L.; Zhang, Q. Evaluation of tetraalkylammonium amino acid ionic liquids as chiral ligands in ligandexchange capillary electrophoresis. J. Chromatogr. A 2020, 1611, 460579. [CrossRef] [PubMed]

19. Végvári, Á.; Kilár, F.; Schmid, M.G.; Gübitz, P.G. Chiral separation of a-amino acids by ligand-exchange capillary electrophoresis using N-(2-hydroxy-octyl)-L-4-hydroxyproline as a selector. Electrophoresis 1998, 19, 2109-2112. [CrossRef]

20. Jiang, J.; Mu, X.; Qiao, J.; Su, Y.; Qi, L. New chiral ligand exchange capillary electrophoresis system with chiral amino amide ionic liquids as ligands. Talanta 2017, 175, 451-456. [CrossRef]

21. Mu, X.; Qi, L.; Qiao, J.; Yang, X.; Ma, H. Enantioseparation of dansyl amino acids and dipeptides by chiral ligand exchange capillary electrophoresis based on $\mathrm{Zn}(\mathrm{II})$-L-hydroxyproline complexes coordinating with gamma-cyclodextrins. Anal. Chim. Acta 2014, 846, 68-74. [CrossRef]

22. Pittler, E.; Grawatsch, N.; Paul, D.; Gubitz, G.; Schmid, M.G. Enantioseparation of amino acids, alpha-hydroxy acids, and dipeptides by ligand-exchange CEC using silica-based chiral stationary phases. Electrophoresis 2009, 30, 2897-2904. [CrossRef] [PubMed]

23. Mizrahi, S.; Rizkov, D.; Shames, A.I.; Lev, O. Chiral separation of dansyl amino acids by ligand exchange capillary electrochromatography in a low molecular weight organogel. Electrophoresis 2008, 29, 3941-3948. [CrossRef]

24. Chuang, S.C.; Chang, C.Y.; Liu, C.Y. Polystyrene monolithic column functionalized with copper-iminodiacetate complex as a stationary phase for open tubular capillary electrochromatography. J. Chromatogr. A 2004, 1044, 229-236. [CrossRef] [PubMed]

25. Wan, H.; Blomberg, L.G. Chiral separation of amino acids and peptides by capillary electrophoresis. J. Chromatogr. A 2000, 875, 43-88. [CrossRef]

26. Zhang, Y.; Huang, L.; Chen, Q.; Chen, Z. A Silica Monolithic Column with Chemically Bonded L-Pipecolic Acid as Chiral Stationary Phase for Enantiomeric Separation of Dansyl Amino Acids by CEC-MS. Chromatographia 2012, 75, 289-296. [CrossRef]

27. Zeng, R.; Luo, Z.; Zhou, D.; Cao, F.; Wang, Y. A novel PEG coating immobilized onto capillary through polydopamine coating for separation of proteins in CE. Electrophoresis 2010, 31, 3334-3341. [CrossRef]

28. Wei, Q.; Zhang, F.; Li, J.; Li, B.; Zhao, C. Oxidant-induced dopamine polymerization for multifunctional coatings. Polym. Chem. 2010, 1, 1430-1433. [CrossRef]

29. Lee, H.; Dellatore, S.M.; Miller, W.M.; Messersmith, P.B. Mussel-Inspired Surface Chemistry for Multifunctional Coatings. Science 2007, 318, 426-430. [CrossRef] [PubMed]

30. Zhang, Y.; Zhang, Y.; Chen, W.; Zhang, Y.; Zhu, L.; He, P.; Wang, Q. Enantiomeric separation of tryptophan by open-tubular microchip capillary electrophoresis using polydopamine/gold nanoparticles conjugated DNA as stationary phase. Anal. Methods 2017, 9, 3561-3568. [CrossRef]

31. Guo, H.; Niu, X.; Pan, C.; Yi, T.; Chen, H.; Chen, X. A novel in situ strategy for the preparation of a beta-cyclodextrin/polydopaminecoated capillary column for capillary electrochromatography enantioseparations. J. Sep. Sci. 2017, 40, 2645-2653. [CrossRef] [PubMed]

32. Liu, C.M.; Liang, R.P.; Wang, X.N.; Wang, J.W.; Qiu, J.D. A versatile polydopamine platform for facile preparation of protein stationary phase for chip-based open tubular capillary electrochromatography enantioseparation. J. Chromatogr. A 2013, 1294, 145-151. [CrossRef]

33. Huang, Y.; Yi, G.; Ji, B.; Gao, D.; Bai, Y.; Liu, Y.; Wang, L.; Xia, Z.; Fu, Q. In situ one-pot synthesis of polydopamine/octadecylamine co-deposited coating in capillary for open-tubular capillary electrochromatography. J. Chromatogr. A 2020, 1610, 460559. [CrossRef] [PubMed]

34. Yi, G.; He, J.; Ji, B.; Gao, D.; Zhang, K.; Wang, L.; Zeng, J.; Xia, Z.; Fu, Q. Solvothermal-assisted in situ rapid growth of octadecylamine functionalized polydopamine-based permanent coating as stationary phase for open-tubular capillary electrochromatography. J. Chromatogr. A 2020, 1628, 461436. [CrossRef]

35. Fu, Q.; Li, X.; Zhang, Q.; Yang, F.; Wei, W.; Xia, Z. A facile and versatile approach for controlling electroosmotic flow in capillary electrophoresis via mussel inspired polydopamine/polyethyleneimine co-deposition. J. Chromatogr. A 2015, 1416, 94-102. [CrossRef] [PubMed]

36. Proniewicz, L.M.; Paluszkiewicz, C.; Wesełucha-Birczyńska, A.; Majcherczyk, H.; Barański, A.; Konieczna, A. FT-IR and FT-Raman study of hydrothermally degradated cellulose. J. Mol. Struct. 2001, 596, 163-169. [CrossRef]

37. Zhu, L.; Lu, Y.; Wang, Y.; Zhang, L.; Wang, W. Preparation and characterization of dopamine-decorated hydrophilic carbon black. Appl. Surf. Sci. 2012, 258, 5387-5393. [CrossRef]

38. Srikanth, K.E.; Veeraiah, A.; Pooventhiran, T.; Thomas, R.; Solomon, K.A.; Raju, C.J.S.; Latha, J.N.L. Detailed molecular structure (XRD), conformational search, spectroscopic characterization (IR, Raman, UV, fluorescence), quantum mechanical properties and bioactivity prediction of a pyrrole analogue. Heliyon 2020, 6, e04106. [CrossRef]

39. Mane, P.S.; Salunke, S.M.; More, B.S. Synthesis and Structural Studies of Transition Metal Complexes with Bidentate Schiff Base Derived from 3-Acetyl-6-methyl-(2H)-pyran-2,4(3H)-dione. E-J. Chem. 2011, 8, 245-252. [CrossRef]

40. Pantoja, M.; Díaz-Benito, B.; Velasco, F.; Abenojar, J.; del Real, J.C. Analysis of hydrolysis process of $\gamma$-methacryloxypropyltrimethoxysilane and its influence on the formation of silane coatings on 6063 aluminum alloy. Appl. Surf. Sci. 2009, 255, 6386-6390. [CrossRef]

41. Fu, Q.; Zhang, K.; Gao, D.; Wang, L.; Yang, F.; Liu, Y.; Xia, Z. Escherichia coli adhesive coating as a chiral stationary phase for open tubular capillary electrochromatography enantioseparation. Anal. Chim. Acta 2017, 969, 63-71. [CrossRef] [PubMed] 
42. Wei, H.; Ren, J.; Han, B.; Xu, L.; Han, L.; Jia, L. Stability of polydopamine and poly(DOPA) melanin-like films on the surface of polymer membranes under strongly acidic and alkaline conditions. Colloids Surf. B Biointerfaces 2013, 110, 22-28. [CrossRef] [PubMed]

43. Chen, Z.; Hobo, T. Chemically L-Phenylalaninamide-Modified Monolithic Silica Column Prepared by a Sol-Gel Process for Enantioseparation of Dansyl Amino Acids by Ligand Exchange-Capillary Electrochromatography. Anal. Chem. 2001, 73, 3348-3357. [CrossRef]

44. Schmid, M.G.; Grobuschek, N.; Tuscher, C. Chiral separation of amino acids by ligand-exchange capillary electrochromatography using continuous beds. Electrophoresis 2000, 21, 3141-3144. [CrossRef]

45. Hillar, M. Glutamate Dehydrogenase. Bioenergetics 1974, 6, 89-124. [CrossRef] 